American Journal of Infectious Diseases 3 (4): 195-201, 2007

ISSN 1553-6203

(C) 2007 Science Publications

\title{
Nutritional control of HIV-AIDS- A case for Selenium
}

\author{
${ }^{1}$ Parisa Kalantari, ${ }^{1}$ Hema Vunta, ${ }^{1}$ Umamaheswari D. Palempalli, ${ }^{1}$ C. Channa Reddy, \\ ${ }^{2}$ Andrew J. Henderson, and ${ }^{2}$ K. Sandeep Prabhu \\ ${ }^{1}$ Center for Molecular Immunology and Infectious Disease, Department of Veterinary and Biomedical \\ Sciences, 115 Henning Building, The Pennsylvania State University, \\ University Park, PA 16802 \\ ${ }^{2}$ Center for HIV/AIDS Care and Research, 650 Albany Street, EBRC 645, Boston University Medical \\ Center, Boston, MA 02118
}

\begin{abstract}
Selenium (Se) is a micronutrient that is incorporated into proteins. Some of the selenoenzymes such as GPXs and thioredoxin reductases exhibit glutathione peroxidase-dependent activities towards organic and inorganic peroxides. Thus, selenoenzymes play a pivotal role in mitigating oxidative stress caused by accumulation of peroxides. In this respect, selenoproteins may interfere with the transcription-driven by oxidative stress-dependent signaling mechanisms to influence the expression of redox sensitive genes, including inflammatory cytokines and HIV provirus. Several epidemiological studies support our view that Se supplementation affects transcription of HIV; however, the underlying mechanism is not elucidated. In this mini review, we consider the relationship between Se and HIV and propose possible mechanisms by which Se controls HIV transcription.
\end{abstract}

Keywords: Tat, NF- $\mathrm{\kappa B}$, thioredoxin reductase, transcription

\section{INTRODUCTION}

Selenium nutrition and optimal health: Selenium is a nutritionally essential trace element that is important for optimal immunity ${ }^{[1-4]}$. Several studies demonstrate that Se deficiency leads to impaired immune responsiveness, while Se-supplementation results in increased immunocompetence $^{[4]}$. Selenium deficiency has been associated with several pathological conditions, including cardiovascular diseases $^{[5]}$, rheumatoid arthritis ${ }^{[6]}$, cancer $^{\left[{ }^{7} \text {, }\right.}$ ${ }^{8]}$ and the focus of this review, AIDS ${ }^{[9]}$. Sesupplementation results in significant increases in tumor cytotoxicity of macrophages and natural killer cells ${ }^{[3]}$. Furthermore, there is an inverse causal relationship of Se intake with cancer risk, notably in adult populations of the United Kingdom, Europe, China, and New Zealand. Even in the United States, mortality rates for cancer were found to be higher in low Se counties ${ }^{[10 ; 11]}$. Based on several studies examining the correlation between $\mathrm{Se}$ and disease resistance, the National Academy of Sciences (USA), has recommended a daily intake of $55 \mu \mathrm{g} /$ day, with a tolerable upper daily intake of $\mathrm{Se}$ at $400 \mu \mathrm{g}^{[12]}$. Furthermore, with changing life styles and eating habits, plasma Se levels appear to be on a downward trend towards deficiency. In particular, cigarette smokers, breast cancer patients and HIV infected individuals, have plasma $\mathrm{Se}$ levels that are significantly reduced $^{[13-15]}$.

Selenium regulates NF- $\mathrm{kB}$ dependent pathways and the expression of pro-inflammatory genes: Since the recent discovery of selenocysteine (SeCys) as the $21^{\text {st }}$ amino acid in proteins, the field of $\mathrm{Se}$ biology has rapidly expanded. There are at least 30 mammalian selenoproteins that have been characterized to date, which contain SeCys incorporated in response to a specific in-frame UGA codon $^{[16-19]}$. These selenoproteins have different cellular functions, but in those selenoproteins for which the function is known, SeCys is located at the active center. The best characterized selenoenzymes belong to the families of Se-GPXs (GPX1-5) and TrxRs. The activities of these enzymes are responsible for Se action as as an dietary antioxidant $^{[17,18,20]}$. Furthermore, thioredoxin (Trx) reductase (TrxR), acts as a "redox switch" to regulate the activities of cellular growth factors and signaling

Corresponding Authors: K. Sandeep Prabhu Andrew J. Henderson and C. Channa Reddy 
by catalyzing oxidation-reduction reactions of critical thiol groups ${ }^{[8]}$. Se deficiency significantly decreases the expression and activities of Se-GPXs/TrxRs and a concomitant increase in ROS production ${ }^{[21,22]}$. Furthermore, Se deficiency increases the sensitivity of cells to oxidative stress ${ }^{[23]}$. Selenium-dependent GPX is essential for the reduction of $\mathrm{H}_{2} \mathrm{O}_{2}$ and lipid hydroperoxides as well as peroxynitrite ${ }^{[24]}$. More importantly, GSH/Se-GPX system represents the major antioxidant enzyme mechanism to reduce $\mathrm{H}_{2} \mathrm{O}_{2}$ and fatty acid hydroperoxides in macrophages ${ }^{[25]}$.

Recent studies have established Se as a potential regulator of transcription ${ }^{[26]}$ by increasing the binding of nuclear proteins, such as NF- $\mathrm{KB}, \mathrm{NF}-1$, and OCT, to DNA regulatory elements. These transcription factors, in particular NF- $\mathrm{kB}$, which has been shown to be the primary redox-sensitive transcription factor ${ }^{[27-29]}$, regulate transcription of genes associated with inflammation including COX-2, iNOS, and several other proinflammatory chemokines and cytokines such as IL-1, IL-6, MIP-2, and TNF $\alpha^{[30-32]}$ in response to oxidative stress or infection ${ }^{[26]}$ and provides one mechanism by which nutritional Se directly impacts inflammation and diseases.

The NF- $\mathrm{KB} / \mathrm{Rel}$ family of transcription factors is comprised of five members, p65, RelB, c-Rel, p52 and p50. In general, these proteins are retained in the cytoplasm through their association with IKB proteins. Upon signaling, which can be initiated by cytokines, receptor engagement and stress, IкBs are degraded and NF- $\mathrm{KB}$ homo- and heterodimers translocate to the nucleus ${ }^{[33,34]}$. Although progress has been made in identifying the biochemical events that regulate NF- $\mathrm{KB}$ activity, how signals are integrated to control the function of different Rel proteins has yet to be resolved. Recent work has demonstrated that two signaling pathways lead to NF- $\mathrm{KB}$ activation ${ }^{[33,34]}$. The classical pathway, which is associated with signaling in response to inflammation, requires activation of the I $\mathrm{KB}$ kinase (IKK) complex that includes IKK $\alpha, \operatorname{IKK} \beta$ and the regulatory subunit NEMO. Active IKK mediates serine specific phosphorylation of $\mathrm{I} \kappa \mathrm{B}$, which triggers polyubiquitination and $26 \mathrm{~S}$ proteasome-dependent degradation, releasing NF- $\mathrm{kB}$ subunits, in particular p65 and p50, to translocate to the nucleus ${ }^{[33,34]}$. NF- $\kappa B$ activity is also induced through an alternative or non-canonical pathway, which requires IKK $\alpha$ activation. IKK $\alpha$ phosphorylates serine residues in the $\mathrm{C}$-terminus of $\mathrm{p} 100$, targeting the $\mathrm{C}$-terminus for degradation and releasing the Rel subunit $\mathrm{p} 52^{[35-37]}$. p52 most commonly dimerizes with RelB and translocates to the nucleus. It has been demonstrated that the alternative pathway is critical for the development of secondary lymphoid organs ${ }^{[34]}$ and regulating macrophage inflammatory activity ${ }^{[38]}$.

Glutathione peroxidase-1 inhibits NF- $\mathrm{KB}$ activation, via inhibition of IKB phosphorylation ${ }^{[39]}$. Therefore, in a state of Se deficiency, GPX1 expression would be diminished leading to IKB phosphorylation and consequent translocation of NF$\mathrm{KB}$ to the nucleus. As a result, inappropriate expression of pro-inflammatory genes and exacerbation of tissue destruction and disease is generally seen. Apart from selenoproteins, there is no evidence for any other gene that is strictly regulated by Se status. However, the accompanying oxidative stress in Se-deficiency leads to an increased expression of oxidative stress-inducible genes such as COX-2, iNOS, and TNF- $\alpha$, which is commonly seen in macrophages.

\section{ROS and macrophage function}

Macrophages play a central role in immune regulation by presenting antigen to T-lymphocytes and ingestion and killing of various invading microorganisms. The cellular response to invading microorganisms is multifaceted with the recruitment and subsequent activation of inflammatory cell populations. Macrophages are critical cellular participants in this process and they are activated by diverse stimuli (like LPS), to synthesize and secrete cytokines, which initiate and control inflammatory and immune functions. Macrophages synthesize numerous substances involved in host defense and inflammation such as complement components, PGs, interleukin (IL)-1 $\beta$, TNF $\alpha$ and other proinflammatory cytokines and chemokines ${ }^{[40]}$. While fulfilling these functions, "activated" macrophages undergo a respiratory burst that produce ROS such as superoxide, hydrogen peroxide $\left(\mathrm{H}_{2} \mathrm{O}_{2}\right)$, hydroxyl and lipid peroxyl radicals. Increases in the intracellular levels of ROS represents a potentially toxic insult, which if not counteracted, will lead to membrane dysfunction, DNA damage, and inactivation of proteins ${ }^{[41]}$. ROS have been implicated in atherosclerosis, rheumatoid arthritis, osteoporosis, asthma, renal disease, Alzheimer's disease, and AIDS; all diseases with a strong inflammatory component ${ }^{[42,43]}$. It is apparent that any condition that disrupts macrophage integrity will have consequences on immune function. Se through the action of GPXs and TrxRs would assure a balanced redox state in macrophages and act as critical 
regulator of macrophage activity, inflammation and cell mediated damage. Along these lines, recent data from our laboratory indicates that there is increased activation of NF- $\mathrm{KB}$ in the macrophage cell line RAW 264.7 when cultured under Se-deficient conditions compared to those cultured in the presence of $\mathrm{Se}^{[44]}$.

Macrophages are important for HIV infection and AIDS. HIV infection results in drastic depletion of $\mathrm{CD} 4^{+}$ $\mathrm{T}$ cells, which is the hallmark of AIDS. However, AIDS is a multifactorial disease affecting multiple organs including the skin, lung, lymphoid tissue and brain ${ }^{[45]}$. The widespread effects of HIV infection are partly due to a general inflammatory response where chronic immune activation leads to an increase in cytokine secretion and enhanced virus replication ${ }^{[46]}$. These events result in tissue damage and the manifestation of several AIDSrelated pathologies ${ }^{[45]}$. Furthermore, the surrounding tissue environment and aberrant cellular activity that is triggered by HIV infection influences virus transcription, replication and alters the susceptibility of cells to $\mathrm{HIV}^{[46]}$.

The complexity and heterogeneity of AIDS underscores that multiple cell types and functions are affected by HIV infection. The primary targets for HIV infection are $\mathrm{CD}^{+} \mathrm{T}$ cells, dendritic cells and macrophages. Tissue resident macrophages, including alveolar macrophages, peritoneal macrophages, Kupffer cells and microglia cells, are productively infected ${ }^{[47-51]}$. Unlike $\mathrm{CD}^{+} \mathrm{T}$ cells, macrophages are resistant to cytopathic effects of HIV and are potentially long-lived reservoirs for persistent infection and dissemination, especially during late stages of AIDS when $\mathrm{CD} 4^{+} \mathrm{T}$ cell counts are low or following withdrawal of anti-viral therapies ${ }^{[52,53]}$. Macrophages are a source of infectious virus in the lymph nodes and lung, and they facilitate HIV entry into many tissues, including the central nervous system $^{[54-57]}$. Furthermore, HIV infection activates macrophages, increasing the expression of TNF $\alpha, \mathrm{IL}-1 \beta$, IL-6 and IL-8, while decreasing production of M-CSF, G$\mathrm{CSF}$ and GM-CSF ${ }^{[26]}$. Elevated levels of IL-1 $\beta$, TNF $\alpha$ and IL-6 have been detected in the serum and cerebrospinal fluid of AIDS patients ${ }^{[45,58]}$. HIV infection has also been suggested to disrupt other macrophages activities including chemotaxis, antigen presentation, phagocytosis and the production of reactive oxygen and nitrogen species ${ }^{[59-63]}$.

Transcriptional control of HIV expression by oxidative stress: HIV provirus expression is regulated at the transcriptional level. Provirus transcription is controlled by the upstream long terminal repeat (LTR), which includes $c i s$-elements that recruit both cellular and viral factors ${ }^{[64,65]}$. The HIV LTR is often divided into four functional units; the Tat activating region (TAR), the promoter, the enhancer, and the modulatory element. The promoter, enhancer and modulatory elements are complex transcriptional elements that bind a plethora of cellular factors; however, few of these sites have been demonstrated to be critical for HIV transcription. Cis-elements that are necessary for efficient HIV replication include sequences for $\mathrm{Sp}-1, \mathrm{NF}-\mathrm{kB}^{[66-71]}$ and, in macrophages, $\mathrm{C} / \mathrm{EBP}^{[65,72,73]}$. It is interesting to note that NF- $\kappa B$ and $\mathrm{C} / \mathrm{EBP} \beta$ are both induced in macrophages by inflammation and oxidative stress suggesting an autocrine pathway that perpetuates macrophage activation and HIV replication.

The TAR element generates an RNA stemloop structure that is recognized by the viral transcription factor Tat. Tat, which is required for HIV replication, increases processive transcription by recruiting P-TEFb to the LTR. In the absence of Tat transcription elongation by RNA polymerase II (Pol II) from the HIV promoter is very inefficient ${ }^{[74,75]}$. Preliminary studies in our laboratories have demonstrated that Tat activity may be modulated by cellular Se status. Furthermore, our analysis has also revealed that several intramolecular disulfides in TAT are potential targets for TrXR. Since TrXR activity is modulated by cellular Se status, these results strongly suggest a mechanistic link between Se and HIV.

Studies on the underlying mechanism of Se in AIDS. Studies in sub-Saharan Africa have shown that Se-supplementation of AIDS patients increased $\mathrm{CD}^{+}$cell counts and decreased the viral titer ${ }^{[76]}$. It is however not clear as to how $\mathrm{Se}$ influences the course of HIV infection. Although, Se deficiency may in part reflect malnutrition and poor health care that would exacerbate the progression of AIDS, we suggest that Se may directly influence HIV replication by two mechanisms (See Fig. 1). One way in which Se influences HIV replication is by its ability to modulate NF- $\mathrm{KB}$ expression; low Se would increase oxidative stress, which in turn would induce $\mathrm{NF}-\mathrm{KB}$ activity and the expression of proinflammatory genes leading to a favorable microenvironment for HIV replication. However, recent data from our laboratory would suggest a second potential pathway in which Se targets Tat activity. Preliminary data have indicated that Se inhibits Tat-dependent induction of the promoter. 


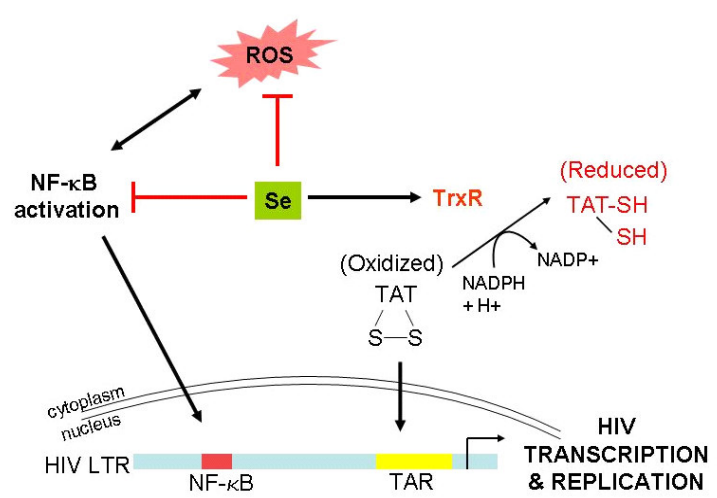

Fig. 1: Schematic representation of the anti-oxidant role of $\mathrm{Se}$ in HIV transcription and replication process. Selenoenzymes prevent activation of NF- $\mathrm{KB}$ by decreasing the oxidant species. TrxRs, in particular, may also play an important role in the redox regulation of Tat.

Furthermore, inhibiting TrxR activity enhances the ability of Tat to induce HIV promoter activity. We hypothesize that TrxR inhibits Tat by reducing active oxidized Tat. Therefore, Se by increasing TrxR activity, would inactive Tat and block HIV replication. Further investigation of how Se regulates HIV expression is required, but these initial observations would suggest that dietary supplementation of Se could complement other anti-viral strategies to effectively manage HIV infection and AIDS.

\section{ACKNOWLEDGMENTS}

We are grateful to the College of Agricultural Sciences, the Huck Institute of the Life Sciences, Penn State University, and NIH AI062467-01 (AJH) and DK07715201 (KSP) for support.

\section{REFERENCES}

1. R.Ebert-Dumig, J.Seufert, D.Schneider, J.Kohrle, N.Schutze, F.Jakob, 1999. Expression of selenoproteins in monocytes and macrophages-implications for the immune system. Med. Klin., 94 (Suppl 3): 29-34

2. L.Kiremidjian-Schumacher, M.Roy, 1998. Selenium and immune function. Z. Ernahrungswiss, 37: 50-6

3. K.S.Kubena, D.N.McMurray, 1996. Nutrition and the immune system: a review of nutrient-nutrient interactions. J. Am. Diet. Assoc., 96: 1156-64
4. R.C.McKenzie, T.S.Rafferty, G.J.Beckett, 1998. Selenium: an essential element for immune function Immunol Today, 19: 342-5

5. D.Azoicai, A.Ivan, M.Bradatean, M.Pavel, L.Jerca, A.Iacobovici, I.Popovici, N.Gheorghita, 1997. The importance of the use of selenium in the role of an antioxidant in preventing cardiovascular diseases. Rev. Med. Chir. Soc. Med. Nat. Iasi., 101: 109-15

6. P.Knekt, M.Heliovaara, K.Aho, G.Alfthan, J.Marniemi, A.Aromaa, 2000. Serum selenium, serum alpha-tocopherol, and the risk of rheumatoid arthritis. Epidemiology, 11: 402-5

7. G.F.Combs, Jr., 1999. Chemopreventive mechanisms of selenium. Med. Klin., 94 (Suppl 3): $18-24$

8. H.E.Ganther, 1999. Selenium metabolism, selenoproteins and mechanisms of cancer prevention: complexities with thioredoxin reductase. Carcinogenesis, 20: 1657-66

9. K.Hori, D.Hatfield, F.Maldarelli, B.J.Lee, K.A.Clouse, 1997. Selenium supplementation suppresses tumor necrosis factor alpha-induced human immunodeficiency virus type 1 replication in vitro. AIDS Res. Hum. Retroviruses, 13: 1325-32

10. L.C.Clark, K.P.Cantor, W.H.Allaway, 1991. Selenium in forage crops and cancer mortality in U.S. counties. Arch.Environ.Health, 46: 37-42

11. M.P.Rayman, 2000. The importance of selenium to human health. Lancet, 356: 233-241

12. N.I.c.Krinsky, 2000. Dietary Reference Intake for Vitamin C, Vitamin E, Selenium, and Carotenoids, National Academy Press, Washington D.C

13. A.M.Preston, 1991. Cigarette smokingnutritional implications. Prog. Food Nutr. Sci., 15: $183-217$

14. S.B.Cole, B.Langkamp-Henken, B.S.Bender, K.Findley, K.A.Herrlinger-Garcia, C.R.Uphold, 2005. Oxidative stress and antioxidant capacity in smoking and nonsmoking men with HIV/acquired immunodeficiency syndrome. Nutr. Clin. Pract., 20: 662-667

15. C.R.Fleming, 1989. Trace element metabolism in adult patients requiring total parenteral nutrition. Am. J. Clin. Nutr., 49: 573-579

16. G.V.Kryukov, S.Castellano, S.V.Novoselov, A.V.Lobanov, O.Zehtab, R.Guigo, V.N.Gladyshev, 2003. Characterization of mammalian selenoproteomes. Science, 300: 1439-1443 
17. T.C.Stadtman, 1996. Selenocysteine. Annu. Rev. Biochem., 65: 83-100

18. V.N.Gladyshev, D.L.Hatfield, 1999. Selenocysteinecontaining proteins in mammals. J. Biomed. Sci., 6: 151-60

19. W.Wen, S.L.Weiss, R.A.Sunde, 1998. UGA codon position affects the efficiency of selenocysteine incorporation into glutathione peroxidase-1. J. Biol. Chem., 273: 28533-28541

20. G.M.Chisolm, D.Steinberg, 2000. The oxidative modification hypothesis of atherogenesis: an overview. Free Radic. Biol. Med., 28: 1815-1826

21. K.E.Hill, G.W.McCollum, M.E.Boeglin, R.F.Burk, 1997. Thioredoxin reductase activity is decreased by selenium deficiency. Biochem. Biophys. Res. Commun., 234: 293-5

22. T.Nakane, K.Asayama, K.Kodera, H.Hayashibe, N.Uchida, S.Nakazawa, 1998. Effect of selenium deficiency on cellular and extracellular glutathione peroxidases: immunochemical detection and mRNA analysis in rat kidney and serum. Free Radic. Biol. Med., 25: 504-11

23. O.Jozanov-Stankov, M.Demajo, I.Djujic, M.Mandic, 1998. Selenium intake as a modulator of responsiveness to oxidative stress. J. Environ. Pathol. Toxicol. Oncol., 17: 251-7

24. J.D.Hayes, L.I.McLellan, 1999. Glutathione and glutathione-dependent enzymes represent a coordinately regulated defence against oxidative stress 2. Free Radic. Res., 31: 273-300

25. N.Chiba, H.Imai, K.Narashima, M.Arai, G.Oshima, M.Kunimoto, Y.Nakagawa, 1999. Cellular glutathione peroxidase as a predominant scavenger of hydroperoxyeicosatetraenoic acids in rabbit alveolar macrophages. Biol. Pharm. Bull., 22: 1047-1051

26. M.J.Christensen, N.W.Pusey, 1994. Binding of nuclear proteins to transcription regulatory elements in selenium deficiency. Biochim. Biophys. Acta., 1225: $338-41$

27. E.Abraham, 2000. NF-kappaB activation. Crit. Care. Med., 28: 100-4

28. M.E.Ginn-Pease, R.L.Whisler, 1998. Redox signals and NF-kappaB activation in $\mathrm{T}$ cells. Free Radic. Biol. Med., 25: 346-61

29. G.K.Rangan, Y.Wang, Y.C.Tay, D.C.Harris, 1999. Inhibition of NFkappaB activation with antioxidants is correlated with reduced cytokine transcription in PTC. Am. J. Physiol., 277: 779-89

30. A.Israel, 2000. The IKK complex: an integrator of all signals that activate NF-kappaB? Trends Cell Biol., 10: 129-33.

31. M.Karin, M.Delhase, 2000. The I kappa B kinase (IKK) and NF-kappa B: key elements of proinflammatory signalling. Semin. Immunol., 12: $85-98$

32. M.M.Shi, I.Chong, J.J.Godleski, J.D.Paulauskis, 1999. Regulation of macrophage inflammatory protein-2 gene expression by oxidative stress in rat alveolar macrophages. Immunology, 97: 30915

33. G.Bonizzi, M.Karin, 2004. The two NF-kappaB activation pathways and their role in innate and adaptive immunity. Trends Immunol., 25: 280288

34. M.S.Hayden, S.Ghosh, 2004. Signaling to NFkappaB. Genes Dev., 18: 2195-2224

35. U.Senftleben, Y.Cao, G.Xiao, F.R.Greten, G.Krahn, G.Bonizzi, Y.Chen, Y.Hu, A.Fong, S.C.Sun, M.Karin, 2001. Activation by IKKalpha of a second, evolutionary conserved, NF-kappa B signaling pathway. Science, 293: 1495-1499

36. E.Dejardin, N.M.Droin, M.Delhase, E.Haas, Y.Cao, C.Makris, Z.W.Li, M.Karin, C.F.Ware, D.R.Green, 2002. The lymphotoxin-beta receptor induces different patterns of gene expression via two NF-kappaB pathways. Immunity, 17: 525535

37. G.Xiao, E.W.Harhaj, S.C.Sun, 2001. NFkappaB-inducing kinase regulates the processing of NF-kappaB2 p100. Mol. Cell, 7: 401-409

38. T.Lawrence, M.Bebien, G.Y.Liu, V.Nizet, M.Karin, 2005. IKKalpha limits macrophage NF-kappaB activation and contributes to the resolution of inflammation. Nature, 434: 11381143

39. C.Kretz-Remy, P.Mehlen, M.E.Mirault, A.P.Arrigo, 1996. Inhibition of I kappa B-alpha phosphorylation and degradation and subsequent NF-kappa B activation by glutathione peroxidase overexpression. J. Cell Biol., 133: 1083-93

40. C.P.Speer, M.Gahr, 1989. The monocytemacrophage system in the human. Monatsschr. Kinderheilkd, 137: 390-5

41. B.Halliwell, J.M.C.Gutteridge, 1989. Free Radicals in Biology and Medicine, Clarendon Press, Oxford

42. A.Spector, 2000. Review: Oxidative stress and disease. J. Ocul. Pharmacol. Ther., 16: 193-201

43. S.Toyokuni, 1999. Reactive oxygen speciesinduced molecular damage and its application in pathology. Pathol. Int., 49: 91-102

44. K.S.Prabhu, F.Zamamiri-Davis, J.B.Stewart, J.T.Thompson, L.M.Sordillo, C.C.Reddy, 2002. Selenium deficiency increases the expression of inducible nitric oxide synthase in RAW 264.7 
macrophages: role of nuclear factor-kappa B in upregulation. Biochem. J., 366: 203-209

45. A.S.Fauci, 1993. Multifactorial nature of human immunodeficiency virus disease: implications for therapy. Science, 262: 1011-1018

46. O.J.Cohen, A.Kinter, A.S.Fauci, 1997. Host factors in the pathogenesis of HIV disease. Immunol. Rev., 159: $31-48$

47. S.Gartner, 2000. HIV infection and dementia. Science, 287: 602-604

48. M.Kaul, G.A.Garden, S.A.Lipton, 2001.Pathways to neuronal injury and apoptosis in HIV-associated dementia. Nature, 410: 988-994

49. A.M.Kesson, W.R.Fear, F.Kazazi, J.M.Mathijs, J.Chang, N.J.King, A.L.Cunningham, 1993.Human immunodeficiency virus type 1 infection of human placental macrophages in vitro. J. Infect. Dis., 168: 571-579

50. K.Olafsson, M.S.Smith, P.Marshburn, S.G.Carter, S.Haskill, 1991. Variation of HIV infectibility of macrophages as a function of donor, stage of differentiation, and site of origin. J. Acquir. Immune. Defic. Syndr., 4: 154-164

51. M.P.Schmitt, A.M.Steffan, J.L.Gendrault, D.Jaeck, C.Royer, C.Schweitzer, C.Beyer, C.Schmitt, A.M.Aubertin, A.Kirn, 1990. Multiplication of human immunodeficiency virus in primary cultures of human Kupffer cells--possible role of liver macrophage infection in the physiopathology of AIDS. Res.Virol., 141: 143-152

52. D.D.Ho, A.U.Neumann, A.S.Perelson, W.Chen, J.M.Leonard, M.Markowitz, 1995. Rapid turnover of plasma virions and CD4 lymphocytes in HIV-1 infection. Nature, 373: 123-126

53. A.S.Perelson, A.U.Neumann, M.Markowitz, J.M.Leonard, D.D.Ho, 1996. HIV-1 dynamics in vivo: virion clearance rate, infected cell life-span, and viral generation time. Science, 271: 1582-1586

54. A.T.Haase, K.Henry, M.Zupancic, G.Sedgewick, R.A.Faust, H.Melroe, W.Cavert, K.Gebhard, K.Staskus, Z.Q.Zhang, P.J.Dailey, H.H.Balfour, Jr., A.Erice, A.S.Perelson, 1996. Quantitative image analysis of HIV-1 infection in lymphoid tissue. Science, 274: 985-989

55. S.Koenig, H.E.Gendelman, J.M.Orenstein, M.C.Dal Canto, G.H.Pezeshkpour, M.Yungbluth, F.Janotta, A.Aksamit, M.A.Martin, A.S.Fauci, 1986. Detection of AIDS virus in macrophages in brain tissue from AIDS patients with encephalopathy. Science, 233: 1089-1093

56. J.E.Merrill, I.S.Chen, 1991. HIV-1, macrophages, glial cells, and cytokines in AIDS nervous system disease. FASEB J., 5: 2391-2397
57. H.S.Nottet, H.E.Gendelman, 1995. Unraveling the neuroimmune mechanisms for the HIV-1associated cognitive/motor complex. Immunol. Today, 16: 441-448

58. E.C.Breen, A.R.Rezai, K.Nakajima, G.N.Beall, R.T.Mitsuyasu, T.Hirano, T.Kishimoto, O.Martinez-Maza, 1990. Infection with HIV is associated with elevated IL-6 levels and production. J. Immunol., 144: 480-484

59. B.A.Biggs, M.Hewish, S.Kent, K.Hayes, S.M.Crowe, 1995. HIV-1 infection of human macrophages impairs phagocytosis and killing of Toxoplasma gondii. J. Immunol., 154: 61326139

60. K.Kedzierska, R.Azzam, P.Ellery, J.Mak, A.Jaworowski, S.M.Crowe, 2003. Defective phagocytosis by human monocyte/macrophages following HIV-1 infection: underlying mechanisms and modulation by adjunctive cytokine therapy. J. Clin. Virol., 26: 247-263

61. A.Kumar, J.B.Angel, S.Aucoin, W.D.Creery, M.P.Daftarian, D.W.Cameron, L.Filion, F.azMitoma, 1999. Dysregulation of B7.2 (CD86) expression on monocytes of HIV-infected individuals is associated with altered production of IL-2. Clin. Exp. Immunol., 117: 84-91

62. S.Polyak, H.Chen, D.Hirsch, I.George, R.Hershberg, K.Sperber, 1997. Impaired class II expression and antigen uptake in monocytic cells after HIV-1 infection. J. Immunol., 159: 21772188

63. J.Yoo, H.Chen, T.Kraus, D.Hirsch, S.Polyak, I.George, K.Sperber, 1996. Altered cytokine production and accessory cell function after HIV-1 infection. J. Immunol., 157: 1313-1320

64. R.Gaynor, 1992. Cellular transcription factors involved in the regulation of HIV-1 gene expression. Aids, 6: 347-363

65. O.Rohr, C.Marban, D.Aunis, E.Schaeffer, 2003. Regulation of HIV-1 gene transcription: from lymphocytes to microglial cells. J. Leukoc. Biol., 74: 736-749

66. J.Alcami, L.T.Lain de, L.Folgueira, M.A.Pedraza, J.M.Jacque, F.Bachelerie, A.R.Noriega, R.T.Hay, D.Harrich, R.B.Gaynor, 1995. Absolute dependence on kappa B responsive elements for initiation and Tatmediated amplification of HIV transcription in blood CD4 T lymphocytes. EMBO J., 14: 15521560

67. J.Y.Kim, F.Gonzalez-Scarano, S.L.Zeichner, J.C.Alwine, 1993. Replication of type 1 human immunodeficiency viruses containing linker 
substitution mutations in the -201 to -130 region of the long terminal repeat. J.Virol., 67: 1658-1662

68. J.Leonard, J.S.Khillan, H.E.Gendelman, A.Adachi, S.Lorenzo, H.Westphal, M.A.Martin, M.S.Meltzer, 1989. The human immunodeficiency virus long terminal repeat is preferentially expressed in Langerhans cells in transgenic mice. AIDS Res. Hum. Retroviruses, 5: 421-430

69. Y.Lu, M.Stenzel, J.G.Sodroski, W.A.Haseltine, 1989. Effects of long terminal repeat mutations on human immunodeficiency virus type 1 replication. J. Virol., 63: 4115-4119

70. C.Parrott, T.Seidner, E.Duh, J.Leonard, T.S.Theodore, A.Buckler-White, M.A.Martin, A.B.Rabson, 1991. Variable role of the long terminal repeat $\mathrm{Sp1-binding} \mathrm{sites} \mathrm{in} \mathrm{human} \mathrm{immunodeficiency}$ virus replication in $\mathrm{T}$ lymphocytes. J. Virol., 65: 1414-1419

71. .K.Ross, A.J.Buckler-White, A.B.Rabson, G.Englund, M.A.Martin, 1991. Contribution of NFkappa B and Sp1 binding motifs to the replicative capacity of human immunodeficiency virus type 1 : distinct patterns of viral growth are determined by $\mathrm{T}$ cell types. J. Virol., 65: 4350-4358
72. .J.Henderson,

K.L.Calame, 1997. CCAAT/enhancer binding protein (C/EBP) sites are required for $\mathrm{HIV}-1$ replication in primary macrophages but not CD4(+) T cells. Proc. Natl. Acad. Sci. U.S.A., 94: 8714-8719

73. A.J.Henderson, R.I.Connor, K.L.Calame, 1996. C/EBP activators are required for HIV-1 replication and proviral induction in monocytic cell lines. Immunity, 5: 91-101

74. S.Y.Kao, A.F.Calman, P.A.Luciw, B.M.Peterlin, 1987. Anti-termination of transcription within the long terminal repeat of HIV-1 by tat gene product. Nature, 330: 489-493

75. F.Laspia, A.P.Rice, M.B.Mathews, 1989. HIV1 Tat protein increases transcriptional initiation and stabilizes elongation. Cell, 59: 283-292

76. R.Kupka, G.I.Msamanga, D.Spiegelman, N.Rifai, D.J.Hunter, W.W.Fawzi, 2005. Selenium levels in relation to morbidity and mortality among children born to HIV-infected mothers. Eur. J. Clin. Nutr., 59: 1250-1258. 